\title{
Structural, Optical, Luminescent and Magnetic Properties of Spray Deposited ZnS, ZnS:Mn and ZnS:Cu Thin Films
}

\author{
G. Selvan ${ }^{1,2, *}$ and R. Thiagarajan ${ }^{1}$ \\ 1Department of Physics, Urumu Dhanalakshmi College, Kattur, Tamilnadu, India; gselvan96@gmail.com, \\ rtrudc1962@gmail.com \\ 2Department of Physics, Thanthai Hans Roever College, Perambalur, Tamilnadu, India
}

\begin{abstract}
Objectives: The study aims to investigate the structural, morphological, optical, luminescent and magnetic properties of undoped, Mn-doped, Cu-doped $\mathrm{ZnS}$ thin films. Method/Statistical analysis: Spray technique is adopted to deposit the films on glass substrates maintained at $400^{\circ} \mathrm{C}$. The deposited films were characterized by various techniques to justify the objectives. Findings: The undoped and doped $\mathrm{ZnS}$ thin films exhibit cubic crystal structure with band gap values of $\mathrm{ZnS}$, ZnS:Mn and ZnS:Cu thin films being 3.83, 3.79 and $3.74 \mathrm{eV}$, respectively. Pure ZnS exhibits diamagnetic behaviour; whereas the $\mathrm{ZnS}: \mathrm{Mn}$ and $\mathrm{ZnS}: \mathrm{Cu}$ thin films show paramagnetic and weak ferromagnetic behaviour, respectively. Application/ improvements: The presence of blue, green and yellow band emissions and weak ferromagnetism realized for the $\mathrm{ZnS}: \mathrm{Cu}$ thin film confirms its utility in luminescent devices and spintronic device applications.
\end{abstract}

Keywords: Structural, Optical, Luminescence, Spray Deposition, Thin Films

\section{Introduction}

The physical properties of materials in low dimensions like a blue shift in the optical absorption spectrum, increased effective surface area, reactivity, phase-phase transformation, strength, etc makes nanomaterials receive much more attention of research in recent years. Nanostructured metal chalcogenide thin films are used in light-emitting diodes, photo-conductive devices, solar cells, lasers, optical waveguides, and sensors.

Among the metal chalcogenides, zinc sulfide ( $\mathrm{ZnS})$ an important II-VI group semiconductor finds applications in lasers, solar cells, photovoltaic devices, luminescent displays, etc due to its better optical properties. ${ }^{1} \mathrm{ZnS}$ exhibits zinc blende (cubic phase) and wurtzite (hexagonal phase) structures with bandgap energies of $3.54 \mathrm{eV}$ and $3.80 \mathrm{eV}$, respectively. ? $^{2}$ The energy band characteristics of $\mathrm{ZnS}$ make it useful as a phosphor and in thin-film electroluminescent devices. $\underline{3}$ In laser, nonlinear optical, electroluminescent, photoluminescent, spintronic and quantum devices, dilute magnetic semiconductors (DMSs) are widely used. .4 Even though $\mathrm{ZnS}$ possess significant optical and luminescent properties, its use as DMS is very much restricted due to its paramagnetic behaviour. To utilize $\mathrm{ZnS}$ for spintronic applications, its magnetic behaviour must be enhanced which can be achieved through doping. Ferromagnetic orderings in $\mathrm{ZnS}$ has been realized with Co doping by. $\frac{5}{5}$ Ferromagnetic stable state and half metallicity have been realized in $\mathrm{ZnS}$ through Fe doping by. $\underline{6}$ Cr-doped $\mathrm{ZnS}$ showed partially filled intermediate band for both FM and AFM spin alignments. $\underline{?}$ Strong $p$-d hybridization between sulfur and transition metal ions are supposed to induce ferromagnetic stable state in $\mathrm{ZnS} . \underline{8}$ In the present work, manganese (Mn)

${ }^{*}$ Author for correspondence 
and copper $(\mathrm{Cu})$ has been used as dopant ions to induce ferromagnetic orderings in spray deposited $\mathrm{ZnS}$ thin films. In addition to the magnetic properties, optical and luminescent properties were studied and reported.

\section{Experimental Details}

Spray pyrolysis technique is used to deposit undoped, $\mathrm{Mn}$-doped and $\mathrm{Cu}$-doped $\mathrm{ZnS}$ thin films. Zinc acetate $\left[\mathrm{Zn}\left(\mathrm{CH}_{3} \mathrm{COO}\right)_{2} \cdot 2 \mathrm{H}_{2} \mathrm{O}\right]$ and thiourea $\left[\mathrm{SC}\left(\mathrm{NH}_{2}\right)_{2}\right]$ are used as the precursor salts to prepare $\mathrm{ZnS}$ thin films. 0.1 $\mathrm{M}$ of zinc acetate and $0.2 \mathrm{M}$ of thiourea were dissolved in $50 \mathrm{~mL}$ de-ionized water and sprayed on glass substrates heated at $400{ }^{\circ} \mathrm{C}$. Due to pyrolytic decomposition, $\mathrm{ZnS}$ thin films were deposited. To accomplish $\mathrm{Mn}$ and $\mathrm{Cu}$ doping, manganese acetate and cupric chloride each of 5 wt.\% of zinc acetate was added to the precursor solution and sprayed. XRD spectra, SEM images, optical band gap were obtained using X'Pert PRO Analytical PW 340/60 X-ray diffract meter, HITACHI S-3000H scanning electron microscope and LAMBDA-35 UV-vis-NIR double beam spectrophotometer, respectively.

PL spectra and M-H curves were drawn using Varian Cary Eclipse fluorescence spectrometer and Lakeshore 7410 vibrating sample magnetometer, respectively.

\section{Results and Discussion}

\subsection{Structural Studies}

Figure 1 pictures the XRD patterns of undoped, Mn and $\mathrm{Cu}$-doped $\mathrm{ZnS}$ thin films. All the films exhibit a cubic crystal structure of ZnS (JCPDS Card No. 05-0566). A strong ( $\left.\begin{array}{lll}1 & 1 & 1\end{array}\right)$ preferential growth is realized for all the films. No shift in the ( $\left.\begin{array}{llll}1 & 1 & 1\end{array}\right)$ peak position is observed for the $\mathrm{ZnS}: \mathrm{Cu}$ thin films as the ionic radius of $\mathrm{Cu}^{2+}(0.72 \AA)$ is almost comparable to that of $\mathrm{Zn}^{2+}(0.74 \AA)$. However, a shift towards a smaller $2 \theta$ angle observed for the $\mathrm{ZnS}: \mathrm{Mn}$ thin film is due to the fact that $\mathrm{Mn}^{2+}(0.80 \AA)$ ion possesses a larger ionic radius than $\mathrm{Zn}^{2+}$ ion. The lattice parameter values calculated using the relation, $1 / d^{2}-\alpha^{2} /\left(h^{2}+k^{2}\right.$ $\left.+l^{2}\right)$ were $5.396,5.399$ and $5.395 \AA$, respectively for the undoped $\mathrm{ZnS}, \mathrm{ZnS}: \mathrm{Mn}$ and $\mathrm{ZnS}: \mathrm{Cu}$ thin films. Using the Scherrer formula, D $-0.9 \lambda / \beta \cos \theta$, the crystallite size of the films was calculated and found to be 39,36 and 30 $\mathrm{nm}$, respectively for the $\mathrm{ZnS}, \mathrm{ZnS}: \mathrm{Cu}$ and $\mathrm{ZnS}: \mathrm{Mn}$ thin films. The decreased crystallite size value observed for the

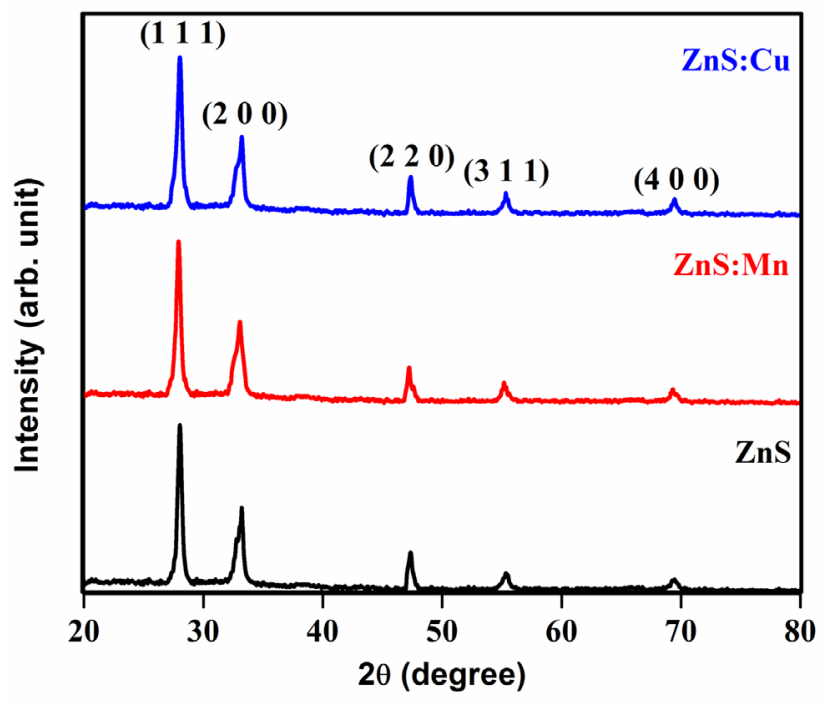

Figure 1. XRD patterns of $\mathrm{ZnS}, \mathrm{ZnS}: \mathrm{Cu}$ and $\mathrm{ZnS}: \mathrm{Mn}$ thin films.

doped films might be due to the drag force exerted by the dopant ions on boundary motion and grain growth.

\subsection{SEM Analysis}

Figure 2 shows the SEM images of a) ZnS, b) ZnS:Mn and c) $\mathrm{ZnS}: \mathrm{Cu}$ thin films. Grains appear to be clustered for pure $\mathrm{ZnS}$. With Mn doping no clustering takes place and the surface got modified with spherical and cubical grains. Nanoneedles are also seen along with few flower shaped grains. The surface of $\mathrm{ZnS}$ got modified with uniformly shaped grains with $\mathrm{Cu}$ doping. Few cloudy regions are also visible.

\subsection{Optical Studies}

From the transmittance spectra (Figure 3), all the films are found to be highly transparent in the visible region with steep optical edges. Both the $\mathrm{ZnS}: \mathrm{Mn}$ and $\mathrm{ZnS}: \mathrm{Cu}$ thin films exhibit better transparency than the pure $\mathrm{ZnS}$ thin film, which might be due to narrow grains size distribution as well as low concentration of defects, such as pits and voids in the films. From the Tauc plots (Figure 4), the bandgap $\left(\mathrm{E}_{\mathrm{g}}\right.$ ) values of the $\mathrm{ZnS}, \mathrm{ZnS}: \mathrm{Mn}$ and $\mathrm{ZnS}: \mathrm{Cu}$ thin films was estimated by extrapolating the straightline portion to zero absorption coefficient value ${ }^{9}$ and was found to be $3.83,3.79$ and $3.74 \mathrm{eV}$, respectively. The reduction in the bandgap values involves the formation of new energy levels close to the valence band edge which 

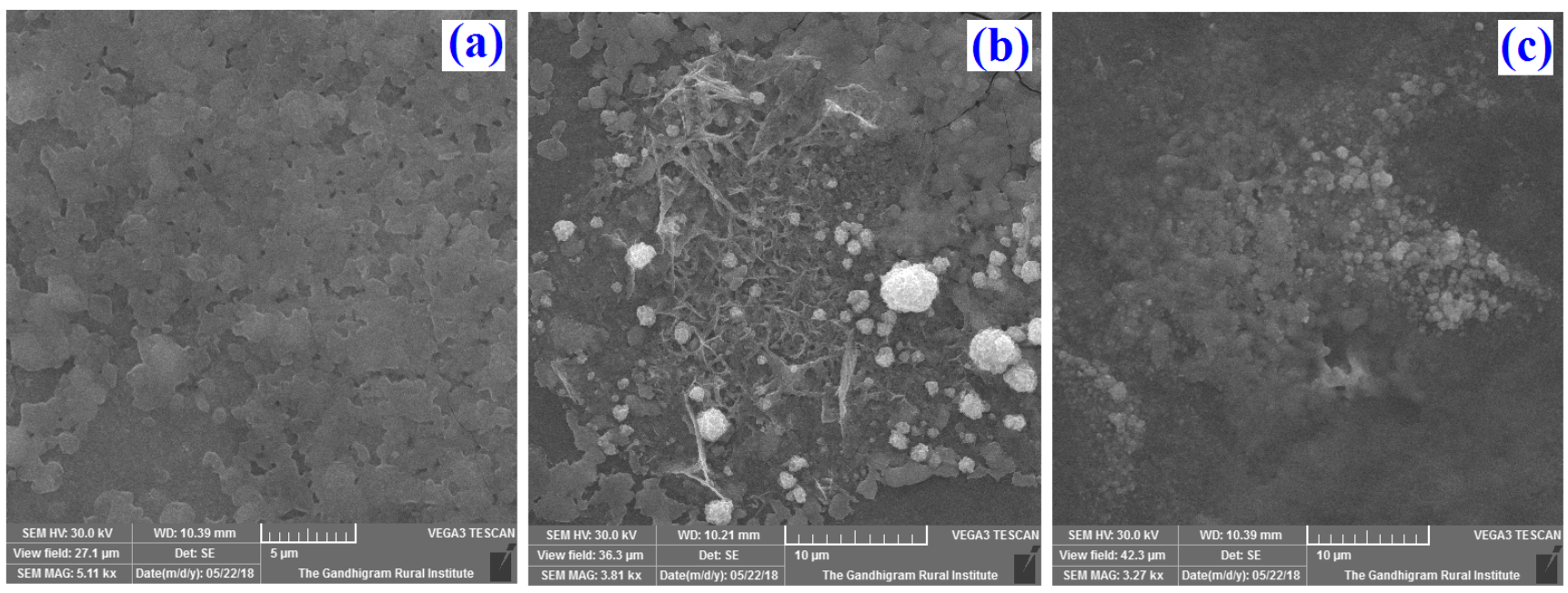

Figure 2. SEM images of a) $\mathrm{ZnS}, \mathrm{b}) \mathrm{ZnS}: \mathrm{Cu}$ and c) $\mathrm{ZnS}: \mathrm{Mn}$ thin films.

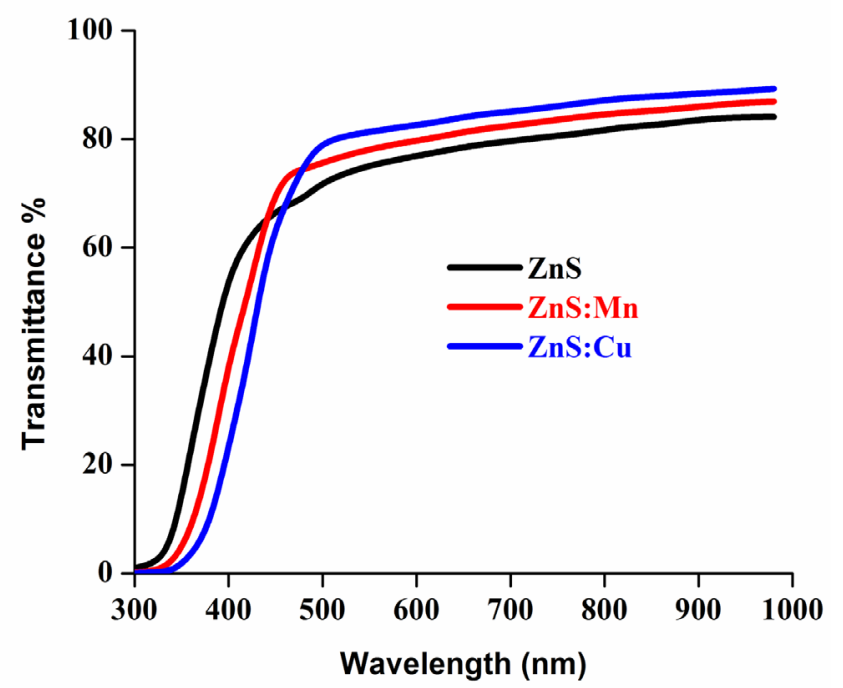

Figure 3. Transmittance spectra of the $\mathrm{ZnS}, \mathrm{ZnS}: \mathrm{Cu}$ and $\mathrm{ZnS}: \mathrm{Mn}$ thin films.

are associated with structural defects. .10 The decreased bandgap values observed with doping may be attributed to the Mass-Burstein effect according to which electronelectron interaction takes place due to increased carrier concentration and hence optical shrinkage is realized.

\subsection{PL Studies}

The room temperature PL spectra of $\mathrm{ZnS}, \mathrm{ZnS}: \mathrm{Cu}$ and $\mathrm{ZnS}: \mathrm{Mn}$ thin films excited at $\lambda=350 \mathrm{~nm}$ are shown in Figure 5. The near band edge (NBE) emission peaks

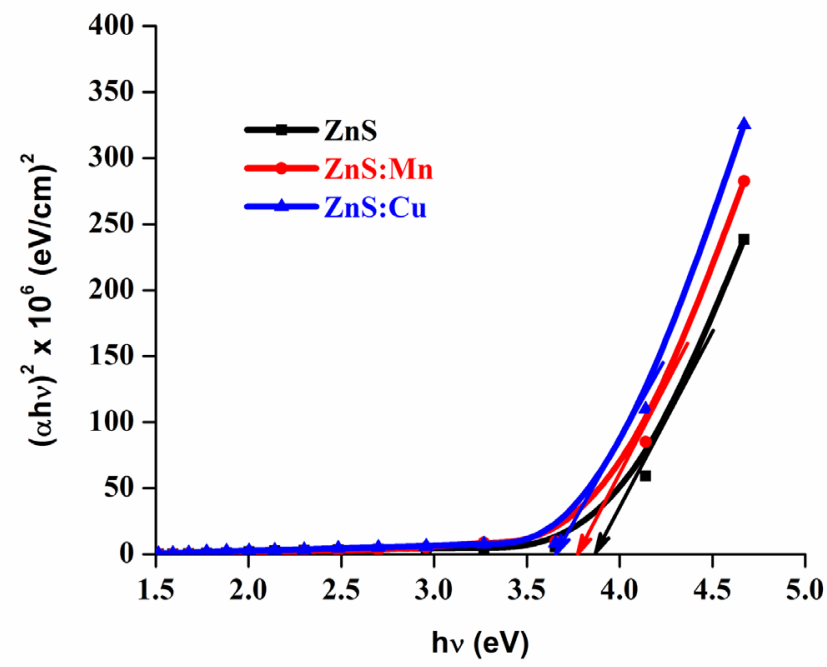

Figure 4. Tauc plots of the $\mathrm{ZnS}, \mathrm{ZnS}: \mathrm{Cu}$ and $\mathrm{ZnS}: \mathrm{Mn}$ thin films.

observed at 361, $377 \mathrm{~nm}$ for pure ZnS, at 360, 372, 384, $391 \mathrm{~nm}$ for the $\mathrm{ZnS}: \mathrm{Cu}$ and at $361,376 \mathrm{~nm}$ for the $\mathrm{ZnS}: \mathrm{Mn}$ thin films are attributed to free exciton annihilation. 11 The recombination between the sulfur-vacancy related donor and the valence band results in the emission of peaks at $411 \mathrm{~nm}$ for $\mathrm{ZnS}, \mathrm{ZnS}: \mathrm{Cu}$ and at $410 \mathrm{~nm}$ for $\mathrm{ZnS}: \mathrm{Mn}$ thin films. Interstitial sulfur lattice defects are responsible for the emission peaks at $437 \mathrm{~nm}$ for pure $\mathrm{ZnS}$ and $\mathrm{ZnS}: \mathrm{Cu}$ and at $436 \mathrm{~nm}$ for the $\mathrm{ZnS}: \mathrm{Mn}$ thin films. The blue emission beaks observed at $461,491 \mathrm{~nm}$ for the $\mathrm{ZnS}: \mathrm{Cu}$ at $490 \mathrm{~nm}$ for pure $\mathrm{ZnS}$, at $491 \mathrm{~nm}$ for the $\mathrm{ZnS}: \mathrm{Mn}$ thin films are due to the transitions of trapped electrons to the valence band. 


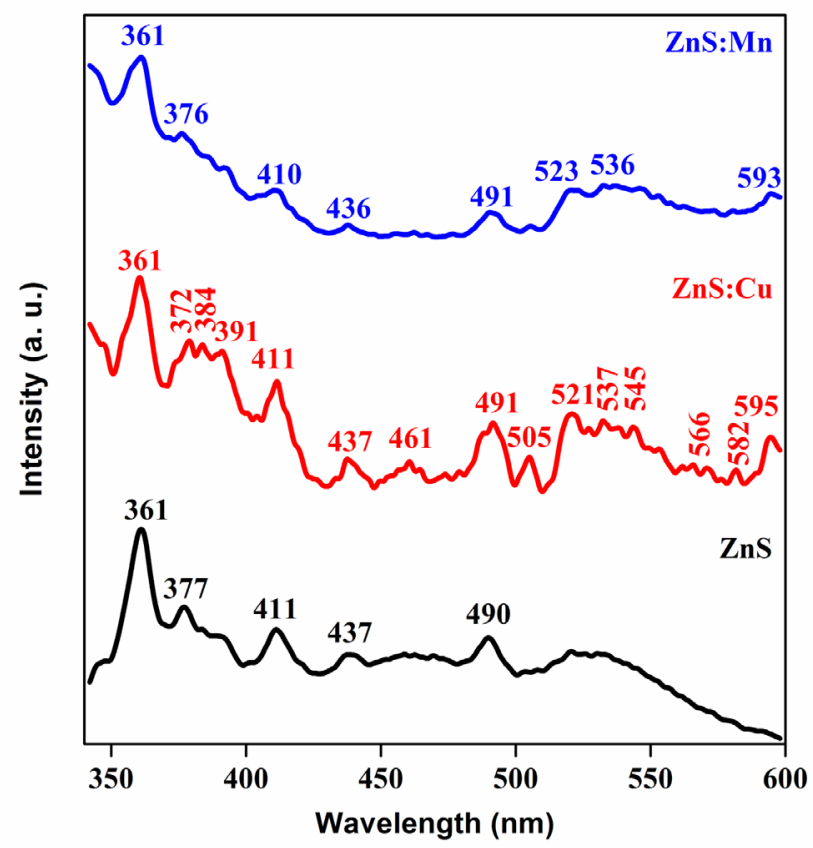

Figure 5. PL spectra of the $\mathrm{ZnS}, \mathrm{ZnS}: \mathrm{Cu}$ and $\mathrm{ZnS}: \mathrm{Mn}$ thin films.

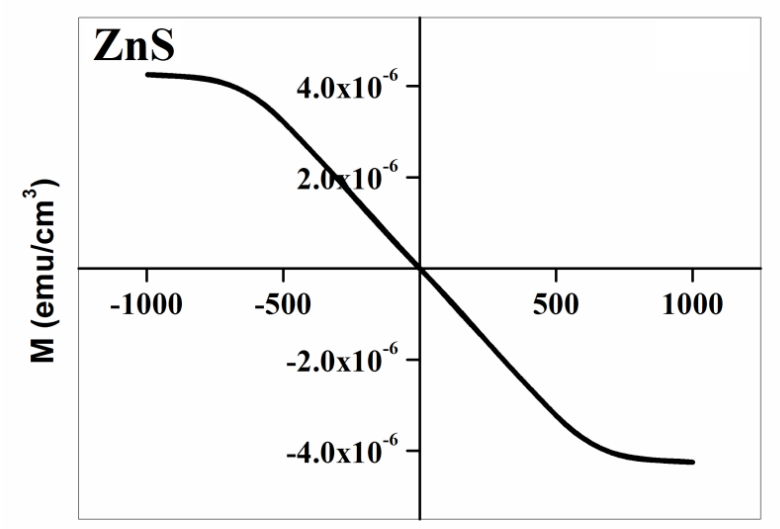

$\mathrm{H}(\mathrm{Oe})$
Electron-hole recombination at trap or imperfection sites is responsible for the emission peaks at 505, 521, $532 \mathrm{~nm}$ for the $\mathrm{ZnS}: \mathrm{Cu}$ and at $523 \mathrm{~nm}$ for the $\mathrm{ZnS}: \mathrm{Mn}$ thin films. The sulfur species on the surface of the films contribute to the emission of the peak at $545 \mathrm{~nm}$ for the $\mathrm{ZnS}$ : $\mathrm{Cu}$ thin film. .12 Emission peaks related to metal interstitials are observed at 566 and $582 \mathrm{~nm}$ for the $\mathrm{ZnS}: \mathrm{Cu}$ thin film. ${ }^{13}$ Donor acceptor pair (DAP) related peaks are observed at $595 \mathrm{~nm}$ for the $\mathrm{ZnS}: \mathrm{Cu}$ and at $593 \mathrm{~nm}$ for the $\mathrm{ZnS}: \mathrm{Mn}$ thin films. 14 The presence of blue, green and yellow band emissions observed for the $\mathrm{ZnS}$ : $\mathrm{Cu}$ thin films confirm its utility in optical luminescent devices.

\subsection{Magnetic Studies}

The room temperature M-H curves of pure $\mathrm{ZnS}$, ZnS:Mn and $\mathrm{ZnS}: \mathrm{Cu}$ thin films are displayed in Figure 6. Undoped $\mathrm{ZnS}$ exhibits diamagnetic behaviour; whereas the $\mathrm{ZnS}: \mathrm{Mn}$ thin film show paramagnetic behaviour and the $\mathrm{ZnS}: \mathrm{Cu}$ thin film exhibits ferromagnetic behaviour. Similar

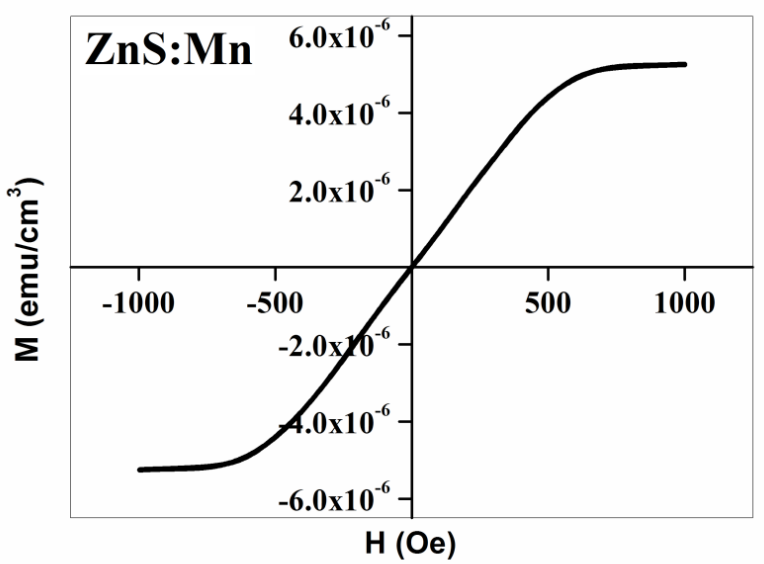

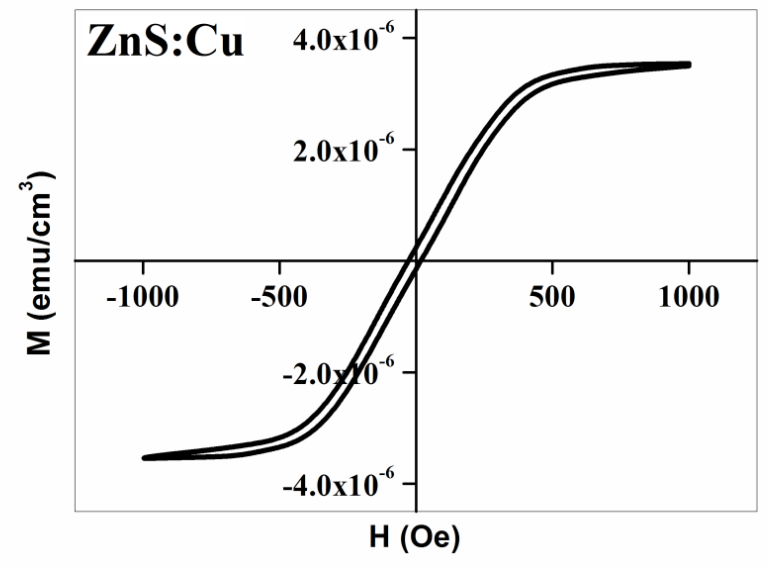

Figure 6. M-H curves of the $\mathrm{ZnS}, \mathrm{ZnS}: \mathrm{Cu}$ and $\mathrm{ZnS}: \mathrm{Mn}$ thin films. 
diamagnetic behaviour has been reported earlier for pure $\mathrm{ZnS}$ thin film by. $\underline{6}$ When $\mathrm{ZnS}$ is doped with $\mathrm{Mn}$, localized spins are provided.

If free carriers are present in the $\mathrm{ZnS}$ matrix, then there might be exchange interaction between the local spin-polarized electrons (electrons of $\mathrm{Mn}^{2+}$ ions) and the free electrons, which leads to their spin polarization effect. Subsequently, the spin-polarized free electrons perform an exchange interaction with local spinpolarized electrons of other $\mathrm{Mn}^{2+}$ ions. Thus, after the long-exchange interaction, almost all $\mathrm{Mn}^{2+}$ ions exhibit the same spin direction, as a result, paramagnetic nature is realized for the $\mathrm{ZnS}: \mathrm{Mn}$ thin film. 15 In the case of $\mathrm{ZnS}: \mathrm{Cu}$ thin film, ferromagnetism is due to the magnetic interactions between the doped $\mathrm{Cu}^{2+}$ ions or from the substitution spin-polarized $\mathrm{Cu}$ atoms in the $\mathrm{ZnS}$ lattice. $\frac{16}{6}$ Vacancy driven $\mathrm{d}^{\circ} \mathrm{FM}$ mechanism also contributes to the ferromagnetic behaviour of the $\mathrm{ZnS}: \mathrm{Cu}$ thin film. ${ }^{17}$

\section{Conclusion}

Thin films of ZnS, Cu-doped ZnS, and Mn-doped ZnS were deposited using the spray pyrolysis technique on glass substrates. From the studies performed it was observed that $\mathrm{Cu}$ and $\mathrm{Mn}$ doping has a profound influence on the properties of pure $\mathrm{ZnS}$. Improved magnetic properties observed for the $\mathrm{ZnS}: \mathrm{Mn}$ and $\mathrm{ZnS}$ :Cu thin films confirmed their potential for spintronic device applications.

\section{References}

1. Firdous A, Aslam Baba M, Singh D, Bhat AH. Optical and impedance studies of pure and Ba-doped $\mathrm{ZnS}$ quantum dots. Appl Nanosci. 2015;5(2):201-6.

2. Hitkari G, Singh S, Pandey G. Structural, optical and photocatalytic study of $\mathrm{ZnO}$ and $\mathrm{ZnO}-\mathrm{ZnS}$ synthesized by chemical method. Nano Struct Nano Objects. 2017:1-9.

3. Yang Y, Huang J, Yang B, Liu S, Shen J. Electroluminescence from ZnS/CdS nanocrystals/polymer composite. Synth Metals. 1997;91(1-3):347-49.

4. Goktas A, Mutlu IH. Structural, optical and magnetic properties of solutions-processed Co-doped $\mathrm{ZnS}$ thin films. J Electron Mater. 2016;45(11):5709-20.

5. Patel SP, Pivin JC, Chawla AK, Chandra R, Kanjilal D, Kumar L. Room temperature ferromagnetism in $\mathrm{Zn}_{1-\mathrm{x}} \mathrm{Co}_{\mathrm{x}} \mathrm{S}$ thin films with wurtzite structure. J Magn Magn Mater. 2011;323(22):2734-40.

6. Akhtar MS, Riaz S, Hussain SS, Naseem S. Magnetic properties of undoped and Fe-doped $\mathrm{ZnS}$ thin films. Adv Civ Environ Mater Res. 2014, 1, pp. 24-28.

7. Tablero C. Electronic and magnetic properties of $\mathrm{ZnS}$ doped with Cr. Phys Rev B. 2006;74(19):195203-11.

8. Chen HX, Shi DN, Qi JS, Wang BL. First principles study on the magnetic properties of transition metal atoms doped $(\mathrm{ZnS})_{12}$ clusters. J Magn Magn Mater. 2011;323(6):781-88.

9. Narasimman V, Nagarethinam VS, Selvan G, Abubacker MP, Balu AR. Bromine doping effect on some properties of CdS films. Surf Eng. 2017;33(3):175-80.

10. Coronado EGA, Gonzalez LA, Angeles JCR, MelendezLira MA, Ramirez-Bon R. Study of the structure and optical properties of $\mathrm{Cu}$ and $\mathrm{Mn}$ in situ doped $\mathrm{ZnS}$ films by chemical bath deposition. Mater Sci Semicond Process. 2018;81:68-74.

11. Ravishankar S, Balu AR, Balamurugan S, Usharani K, Prabha D, Suganya M, et al. TG-DTA analysis, structural, optical and magnetic properties of $\mathrm{PbS}$ thin films doped with $\mathrm{Co}^{2+}$ ions. J Mater Sci Mater Electron. 2018;29(7):6051-58.

12. Suganya M, Balu AR, Anitha S, Prabha D, Balamurugan $\mathrm{S}$, Priyanka B, et al. PbS-NiO nanocomposite material with enhanced magnetic, photocatalytic and antifungal properties. Mater Sci Eng B. 2018;229:118-25.

13. Narasimman V, Nagarethinam VS, Usharani K, Balu AR. Optoelectronic, magnetic and antibacterial properties of Zr-doped CdS thin films. Optik. 2017;138:398-406.

14. Abubacker MP, Selvan G, Balu AR. Optoelectronic, magnetic and antifungal properties of CdS thin films co-doped with zinc and bromine. J Mater Sci Mater Electron. 2017;28(14):10433-40.

15. Wang J, Wan J, Chen K. Facile synthesis of superparamagnetic Fe-doped $\mathrm{ZnO}$ nanoparticles in liquid polyols. Mater Lett. 2010;64(21):2373-75.

16. Yildirim OA, Durucan C. Room temperature synthesis of $\mathrm{Cu}$ incorporated $\mathrm{ZnO}$ nanoparticles with room temperature ferromagnetic activity: structural, optical and magnetic characterization. Ceram Int. 2016;42(2):3229-38.

17. Srivind J, Nagarethinam VS, Suganya M, Balamurugan S, Usharani K, Balu AR. NiO coupled $\mathrm{SnS}_{2}$ nanoparticles with improved magnetic and photocatalytic performance against the degradation of organic dyes without $\mathrm{N}=\mathrm{N}$ double bond. Vacuum. 2019;163(1):373-83. 